\title{
Aspirin and Reducing Risk of Gastric Cancer: Systematic Review and Meta-Analysis of the Observational Studies
}

\author{
Thin Thin Win ${ }^{1}$, Saint Nway Aye ${ }^{1}$, Joyce Lau Chui Fern ${ }^{2}$, Cheng Ong Fei ${ }^{2}$
}

1) Pathology Division, School

of Medicine, International Medical University, Kuala Lumpur

2) School of Pharmacy, International Medical University, Kuala Lumpur, Malaysia

\author{
Address for correspondence: \\ Thin Thin Win \\ Pathology Division, School of \\ Medicine, \\ International Medical \\ University, Kuala Lumpur \\ 126, Jalan Jalil Perkasa 19, \\ Bukit Jalil, 57000 Kuala \\ Lumpur, Malaysia \\ thinthinwin@imu.edu.my
}

Received: 01.02.2020

Accepted: 15.04 .2020

\begin{abstract}
Background \& Aims: The latest meta-analysis on the role of aspirin on various cancers was published in early 2018. By including the latest and updated primary observational studies, we aimed to conduct this systematic review and meta-analysis to synthesize stronger evidence on the role of aspirin in reducing gastric cancer (GC) risk.

Methods: The PubMed, Scopus, and MEDLINE databases were systematically searched up to December 2019 to identify relevant studies. Random-effects model was used to calculate summary ORs and $95 \% \mathrm{CI}$ for $\mathrm{I}^{2}>50 \%$. If the heterogeneity is not significant, the fixed-effects model was used. Overall analysis of the studies, inverse variance weighting after transforming the estimates of each study into log OR and its standard error were used. Results: 21 studies were included in this meta-analysis. Results showed that aspirin significantly reduced the $\mathrm{GC}$ risk $(\mathrm{OR}=0.64,95 \% \mathrm{CI}=0.54-0.76)$ with substantial heterogeneity $\left(\mathrm{I}^{2}=96 \%\right)$. Effect of $\mathrm{GC}$ risk reduction in low dose $(\mathrm{OR}=0.80,95 \% \mathrm{CI}=0.59-1.09)$ is slightly greater than high dose aspirin $(\mathrm{OR}=1.08,95 \% \mathrm{CI}=0.77-1.52)$. Protective effect of aspirin uses $>5$ years $(\mathrm{OR}=0.67,95 \% \mathrm{CI}=0.34-1.31)$ was greater than $<5$ years $(\mathrm{OR}=1.01$, $95 \% \mathrm{CI}=0.72-1.43$ )

Conclusion: In conclusion, this meta-analysis showed that low dose aspirin with longer duration of more than 5 years were associated with a statistically significant reduction in GC risk. However, due to possible confounding variables and bias, these results should be cautiously treated.
\end{abstract}

Key words: aspirin - risk of gastric cancer - systematic review - meta-analysis - observational studies.

Abbreviations: GC: gastric cancer; NSAID: non-steroidal anti-inflammatory drug.

\section{INTRODUCTION}

Gastric adenocarcinoma, so called gastric cancer (GC) is the second most common gastrointestinal malignancy and it is the sixth common malignancy worldwide [1]. Although the incidence of GC in western countries has been decreasing, it remains one of the leading causes of cancer mortality worldwide [2]. According to 2019 Cancer Statistics report done by American Cancer Society, new cases of GC in 2019 were 27,510 and estimated deaths due to GC were 11,140 in both sexes [3].

Most of the environmental risk factors of GC are preventable with measures such as eradication of Helicobacter pylori infection, high intake of fresh fruits and vegetables, lowsodium diet, low red meat and sensible alcohol drinking [4-6]. In gastric carcinogenesis, inflammation plays an important role and anti-inflammatory therapy is efficacious towards early neoplastic progression and malignant conversion [7].

Aspirin has been known to have anti-inflammatory and chemo-preventive effect on various cancers including colorectal and gastric cancer $[8,9]$. It is one of the effective non-steroidal anti-inflammatory drugs (NSAIDs) which inhibits the inflammation by suppression of cyclooxygenase (COX)-2 [10, 11].

Many systematic reviews and meta-analyses have assessed the role of aspirin in reducing cancer risk $[12,13]$. However, those studies were on various types of cancer. As aspirin has been used for prevention of atherosclerosis and cardiovascular diseases, there were many primary observational studies both cohort and case-control types. Therefore, by including the latest and updated primary observational studies, we conducted this 
systematic review and meta-analysis to synthesize stronger evidence on the role of aspirin in reducing GC risk.

\section{METHODS}

\section{Literature search strategy}

The systematic literature search was carried out according to "Preferred Reporting Items for Systematic Review and Meta-Analyses" (PRISMA) checklist [14] in three healthrelated databases (PubMed, Scopus, and MEDLINE). Search terms such as "gastric cancer", "stomach cancer", "gastric adenocarcinoma", "aspirin" and "reducing risk" were used to search for relevant studies. Terms from the categories were connected with "OR" within each category and by "AND" between categories. The search was limited to original articles published in the English language up to December 2019. To find out additional studies, reference lists of the original articles were screened through.

\section{Inclusion and exclusion criteria}

Inclusion criteria followed the PICOS format: Population (P), Interventions (I), Comparisons (C), Outcomes (O) and Study design (S) as follow: P: individuals without histologically confirmed GC; I: exposure of aspirin of any dosage and any duration; C: Aspirin user and non-aspirin user, aspirin user and other NSAID or placebo user; O: reduction of GC risk; S: observation studies (both case control and cohort studies.

Studies that did not meet the inclusion criteria were excluded. Review articles, case reports, editorials, and studies that used aspirin with combination of NSAIDs were excluded.

\section{Data Extraction}

Two investigators extracted the data independently and any disagreement was resolved by discussion. Data of the primary studies such as name of author, publication year, country, ethnicity, gender, age group, number of controls, number of cases, study design, aspirin dosage, duration of aspirin uses, site of GC, histological types of GC, odds ratio (OR), hazards ratio (HR) or relative risk (RR) with its $95 \%$ confidence interval $(\mathrm{Cl})$ and any confounding factors in the analysis were extracted.

\section{Assessment of Study Quality}

The quality of eligible studies were assessed by the NewcastleOttawa Quality Assessment Scale [15]. Studies were assessed using three categories, selection of study groups (0-4 points), comparability (0-2 points), and exposure (0-3 points). A total score $\leq$ of 3 was considered low quality, scores between 4-6 moderate quality and scores $\geq 7$ high quality. These scores were used only to facilitate the interpretation of the meta-analysis results, but not used as a criterion for inclusion or exclusion of the studies. During these processes, any discrepancy or disagreement was resolved by discussion to arrive consensus.

\section{Data analysis}

The meta-analysis was conducted to evaluate the effect of aspirin in reducing the GC risk. PRISMA checklist was employed for extraction data, analysis and reporting of observational studies. $\mathrm{I}^{2}$ test was used to measure heterogeneity between these individual studies. Significant heterogeneity is indicated if $\mathrm{p}<0.05$ and, or $\mathrm{I}^{2}>50 \%$ [15]. Some primary studies indicated raw data and some indicated only OR or RR. Therefore, for overall analysis of the studies, we used inverse variance weighting, after transforming the estimates of each study into log OR and its standard error. For subgroup analysis, as all studies for subgroups provided raw data, raw data of aspirin user and non-user were used.

A random-effects model was used to calculate summary ORs and $95 \% \mathrm{CI}$ for $\mathrm{I}^{2}>50 \%$. However, if the heterogeneity was not significant, the fixed effects model was employed. Subgroup analysis were further administered based on cancer sites, dosage, gender, duration, ethnicity and histological types. In subgroup analysis, raw data were used as some primary studies indicated separate data for separate subgroups. In addition, funnel plots were carried out for evaluating bias risk of publication. For all the tests, two tailed $\mathrm{p}$ values were calculated, and it was considered as significant if $p$ value was less than 0.05 . All the meta-analysis tests were carried out by using RevMan 5.3 [16].

\section{RESULTS}

\section{Literature search and study characteristic}

A total of 5,675 studies were identified from three databases (3,529 from PubMed; 154 from Scopus; 1992 from Ebsco). A four-phase flow chart of the study selection process is illustrated in Fig. 1. PubMed Search string was Search (((gastric cancer) OR stomach cancer) OR gastric adenocarcinoma) AND aspirin) AND reducing risk.

After excluding duplicate studies, animal studies, in vitro studies, case reports, reviews and other non-relevant studies, 563 studies were screened. After the title and abstract screening, 520 studies were excluded as those were studies on aspirin in treating GC cases and effects of aspirin on the progression, recurrence and survival of GC. Forty-six full-text papers were reviewed for eligibility and a final of 21 primary studies met the pre-specified inclusion criteria. A summary of the 25 excluded studies is provided in Supplementary Table I [17-41]. Table I indicates the characteristics of the included studies. Out of 21 included primary studies, 11 studies were case-control studies [42-52] and 10 were cohort studies [53-62]. Seven studies included in this meta-analysis were from the United States [44-47, 53, 55, 61], 5 were from Europe (one each from the United Kingdom, Sweden, Italy, Denmark and Russia) $[42,43,50,52,56]$ and 9 from Asia countries ( 2 from Hong Kong, 4 from Korea, one from Taiwan, Japan and China) $[39,48,49,51,57-60,62]$. The quality assessment of 25 included studies by using Newcastle-Ottawa Quality Assessment Scale is shown in Supplementary Table II.

\section{Aspirin Use and GC}

Twenty-one studies were included to evaluate the overall protective effect of aspirin. There was a significant inverse association between the case-control studies which seemed to have contributed to this significant overall effect compared to the cohort studies. However, there was a high heterogeneity $\left(\mathrm{I}^{2}=96 \%\right.$ ) (Fig. 2). The funnel plot (Fig. 3) showed some degree of publication bias. To overcome the heterogeneity, subgroup analyses (gender, ethnicity, duration of use, aspirin dosage, histological types and sites of GC) were carried out. 


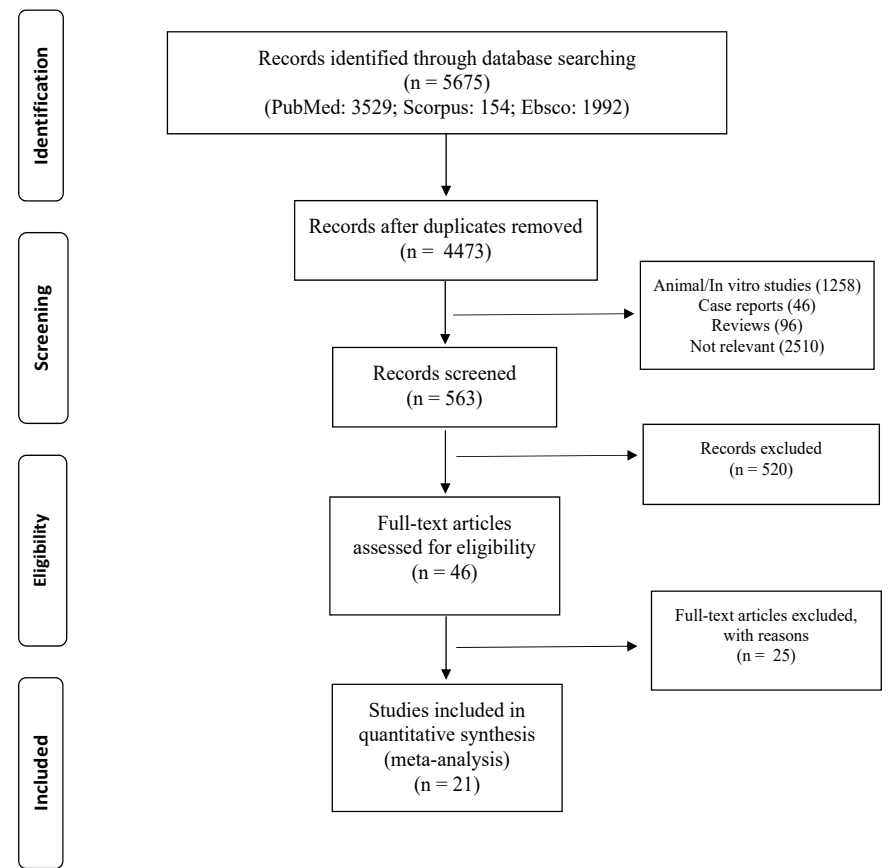

Fig. 1. PRISMA flow chart indicating study selection [14]

\section{Subgroup analyses}

The effect of gender on the use of aspirin and the risk of GC was examined in stratified analyses. Only three studies provided gender specific estimates. Inverse association between use of aspirin and GC risk was more in female $(\mathrm{OR}=0.66$, $95 \% \mathrm{CI}=0.45-0.97)$ than male $(\mathrm{OR}=0.86,95 \% \mathrm{CI}=0.62-1.20)$. However, there was substantial unexplained heterogeneity in the male group with $\mathrm{I}^{2}=59 \%$ and the differences in these subgroups were not statistically significant $(\mathrm{p}=0.31)$ (Fig $4 \mathrm{~A})$. The effect of ethnicity on the use of aspirin and risk of GC was examined in stratified analyses. Inverse association between aspirin use and the risk of GC was seen in the Caucasian population $(\mathrm{OR}=0.82,95 \% \mathrm{CI}=0.67-1.00)$. However, the differences in different ethnic subgroups were not statistically significant $(\mathrm{p}=0.11)$ (Fig. 4B).

In this study, two subgroups for the duration of aspirin use ( $<5$ years and $\geq 5$ years) were defined and the effect of these subgroups were stratified. Six studies provided duration specific estimates. Protective effect of GC by use of aspirin $\geq 5$ years $(\mathrm{OR}=0.67,95 \% \mathrm{CI}=0.34-1.31)$ was more than that of the duration $<5$ years $(\mathrm{OR}=1.01,95 \% \mathrm{CI}=0.72-1.43)$. However, duration subgroup differences were not statistically significant $(\mathrm{p}=0.29)$ although there was an overall heterogeneity of $\mathrm{I}^{2}=84 \%$ with $\mathrm{p}=<0.00001$ (Fig. 5A).

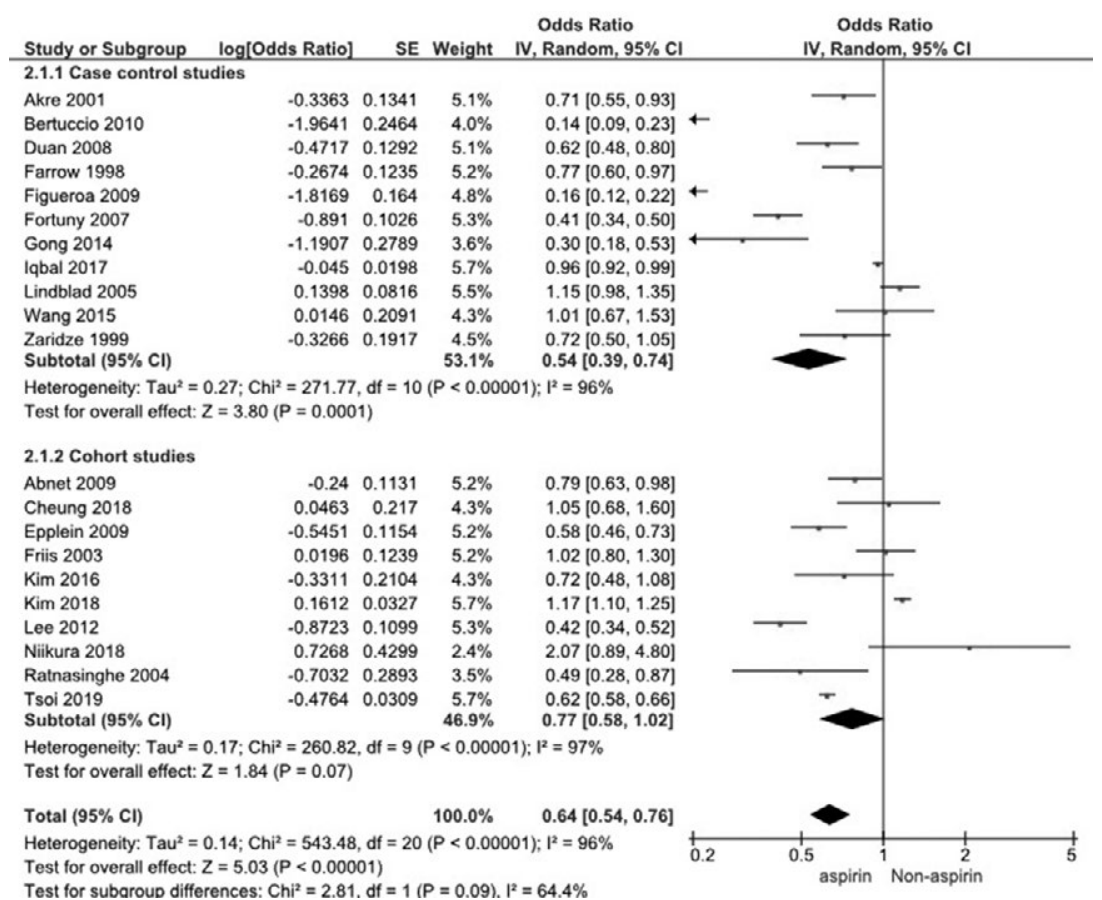

Fig. 2. Forest plot for the association between aspirin use and gastric cancer risk. 


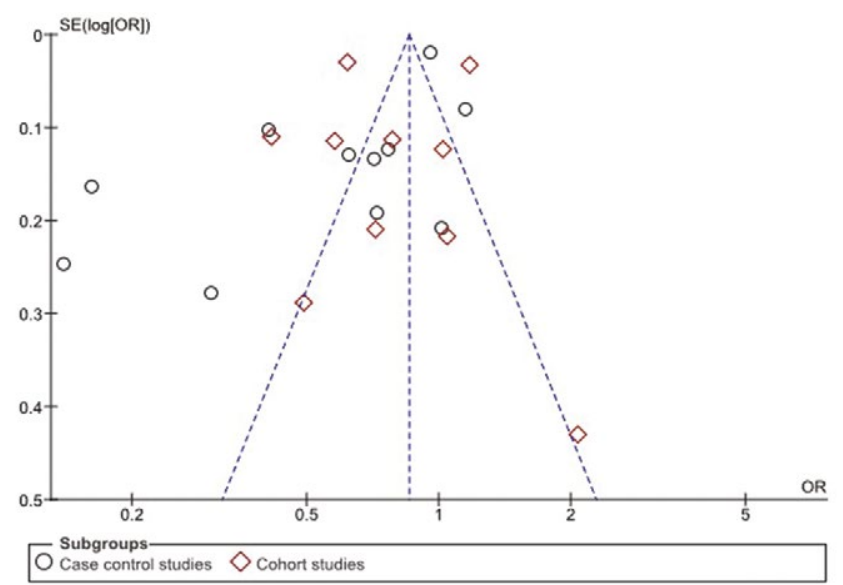

Fig. 3. Funnel plot showing the risk of bias publication.

Most of the included studies did not specifically report the dose; only three studies provided dose specific estimates. Less than $200 \mathrm{mg}$ was considered as a low dose and more than 200 $\mathrm{mg}$ as high dose. There was no statistically significant difference between low dose and high dose aspirin in reducing the GC risk $(p=0.21)$. However, it showed an inverse association between the effect of low dose aspirin and GC risk ( $\mathrm{OR}=0.80$, 95\% CI=0.59-1.09) (Fig. 5B).

The possible association of GC risk in different histological type and use of aspirin was reported by three studies. There were no statistically significant association between aspirin use and histological types of GC $(\mathrm{p}=0.86)$. However, a slight inverse association between aspirin use and reduced risk of diffuse types of $\mathrm{GC}(\mathrm{OR}=0.96,95 \% \mathrm{CI}=0.67-1.37)$ was seen (Fig. $6 \mathrm{~A}$ ). Five studies provided site (cardia and non-cardia) specific estimates of GC risk by the use of aspirin. These subgroup differences were not statistically significant $(p=0.10)$. However, there was a significant inverse association between aspirin use and non-cardia $\mathrm{GC}$ risk $(\mathrm{OR}=0.88,95 \% \mathrm{CI}=0.79-0.99)$ with heterogeneity $\left(\mathrm{I}^{2}=68 \%\right)$ (Fig. 6B).

\section{DISCUSSION}

The first report on the role of aspirin in cancer prevention was on colorectal cancer [63]. Since then, the cancer preventive role of aspirin has been evaluated. Several meta-analyses were performed on the association between the risk of GC and aspirin. Latest published meta-analysis studied the effect of aspirin on various cancers without any subgroup analysis [12]. Another meta-analysis published in 2017 investigated the role of aspirin together with other nonsteroidal anti-inflammatory drugs on GC [64]. In the current study, the overall analysis showed that aspirin significantly reduced the GC risk. As this study was done on observational studies there were some degree of publication bias noted. Results of this study were similar with some previous metaanalyses [12, 13, 64-66]. Our results are discordant with one study [67] which claimed that aspirin decreased the chance of getting non-cardia GC only.

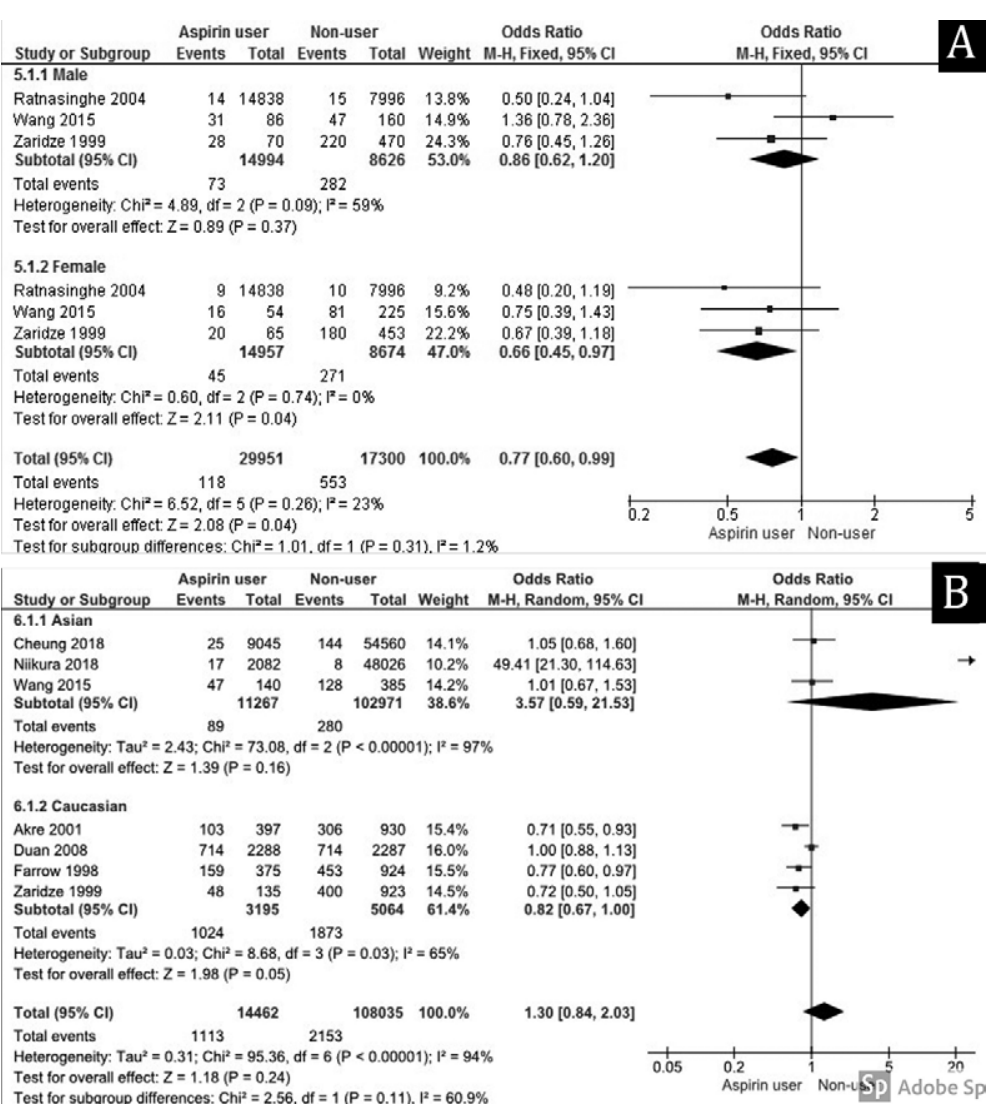

Fig. 4. (A) Forest plot for the association between aspirin use and GC risk in different sexes; (B) Forest plot for the association between aspirin use and different ethnicity. 


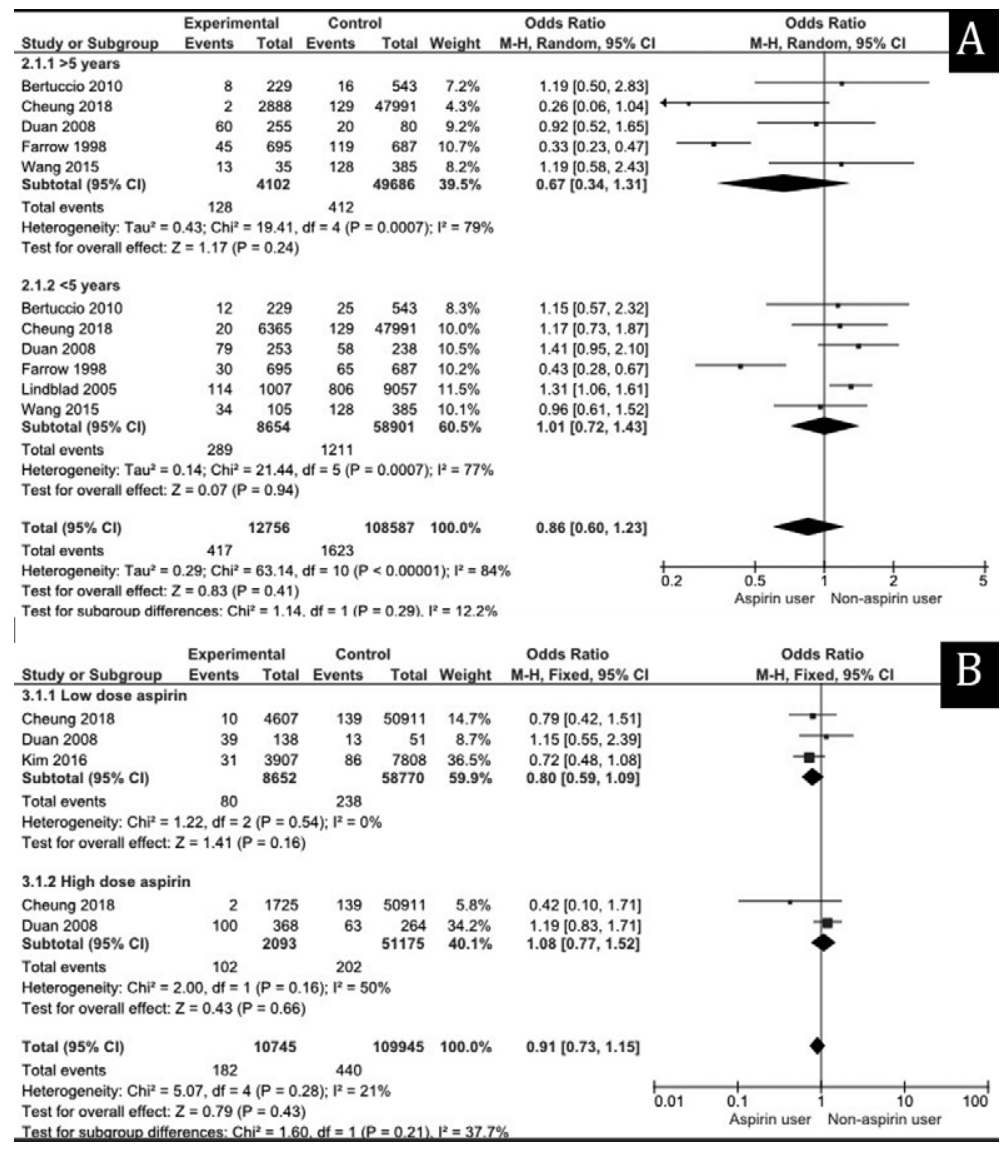

Fig. 5. (A) Forest plot for the association between duration of aspirin use and gastric cancer risk; (B) Forest plot for the association between dose of aspirin use and gastric cancer risk.

As the observational studies are more prone to publication bias $[68,69]$, there was some degree of publication bias noted in this meta-analysis. A study showed that the decreased risk of GC with aspirin was observed in the case-control studies, but not in the cohort studies [12]. However, a study indicated that both case-control studies $(\mathrm{RR}=0.84 ; 95 \% \mathrm{CI}=0.70-1.00)$ and cohort studies $(\mathrm{RR}=0.81 ; 95 \% \mathrm{CI}=0.67-0.98)$ showed an inversed relationship between the aspirin use and the risk of GC [65]. Some meta-analyses on aspirin and GC reported an inverse association $[13,64,66]$ while another meta-analysis found no significant association [67] between the use of aspirin and GC risk.

As included studies were observational studies in this metaanalysis, the duration of observation was variable. Therefore, two groups for duration of aspirin use were defined: $<5$ years, and $\geq 5$ years. Our results showed that the longer duration of aspirin use ( $\geq 5$ years) has significantly reduced the risk of GC. However, pool estimate of duration subgroup differences was not statistically significant. Huang et al. [64] also reported that there were insignificant non-linear relationships between the duration of any NSAIDs use or aspirin use and GC risk. However, Kong et al [65] reported short or middle-term use ( $\leq 5$ years) of aspirin was more effective in reducing GC risk.

In term of dose of aspirin use in this study, it showed that there is no statistically significant difference between low dose and high dose aspirin use in reducing GC risk $(\mathrm{p}=0.21)$. However, the inverse association between low dose aspirin use and reduced GC risk was noted. Most of the included primary studies did not specifically identify the dose and only a few studies identified it. However, we assumed that most studies on GC cases with follow up questioning on aspirin use were found to be of a low dose ( 1 to $<7$ tablets per week). Kim et al [58] reported that defined daily dose (DDD)-year and cumulative dose $>3$ DDD-year has a reduced risk of GC. Huang et al. [64] reported there was a non-linear relationship between the frequency (dose) of aspirin use and GC risk. Low dose aspirin use is also associated with a reduced risk of other cancers such as colorectal, oesophagus and prostate cancer [12]. In general, as the definition of aspirin use and dosage varied among the included primary studies, statistically significant results on dose response was not found in this study.

Although gender subgroup analysis was not statistically significant in this study $(\mathrm{p}=0.31)$, significant inverse association between aspirin use and female GC risk was detected. Qiao et al. [12] reported no significant association with gender. Regarding ethnicity, there was an inverse association between the Caucasian population and a risk of GC compared to the Asian population. However, there was no statistically significant subgroup effect and most of the included studies are of Caucasian in this meta-analysis. Yang et al. [67] also reported that regular aspirin use was associated with a reduced risk of non-cardia GC among Caucasians.

There was no significant association of GC risk based on site and histological type with aspirin use in this study. However, an inverse association between aspirin use and non-cardia GC risk $(\mathrm{OR}=0.88,95 \% \mathrm{CI}=0.79-0.99)$ was noted. This finding is 


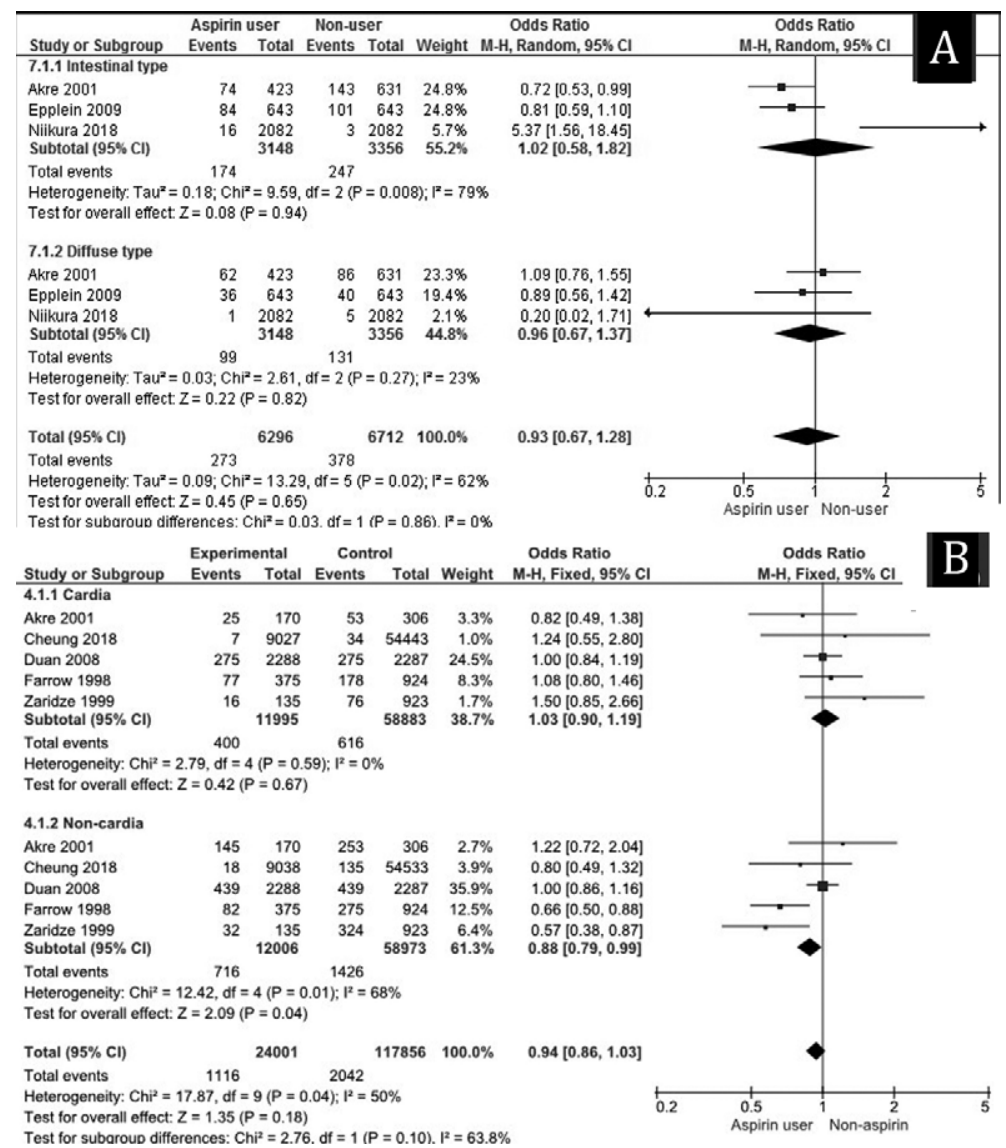

Fig. 6. (A) Forest plot for the association between aspirin use and different histological type of gastric cancer risk; (B) Forest plot for the association between aspirin use and the site of GC risk.

similar to some studies where it was reported that aspirin use was associated with only non-cardia GC but not with cardia GC $[64,67]$. Niikura et al. [60] reported chemo preventive effect of aspirin is greater in diffuse types than intestinal types. In general, all the subgroup analyses in this study showed no statistically significant subgroup effects as all subgroup differences showed $\mathrm{p}$-value $>0.1$.

There were some limitations in this study especially in the subgroup analyses. Many studies did not specifically provide the duration of aspirin use. Duration and dose of aspirin use were not uniform in the included studies. Hence, more studies should be included and a larger sample size of population are required for better evidence towards the protective effect of aspirin on GC. However, many of the excluded studies reported on the combined effect of NSAIDs and aspirin rather than the effect of aspirin only.

\section{CONCLUSION}

This meta-analysis evidenced that low dose aspirin with a longer duration of more than 5 years was inversely associated with a significant reduction in GC risk. However, due to possible confounding variables and bias such as smoking and Helicobater pylori infection, these results should be cautiously treated.

Conflicts of interest: None to declare.
Authors' contribution: T.T.W. and S.N.A. conceived and designed the study. T.T.W., S.N.A., J.L.C.F., C.O.F. data analysis and interpretation. T.T.W drafted and revised the paper.

Acknowledgements: The authors are grateful to the participants and researchers of the primary studies in this meta-analysis and to the International Medical University (IMU) Malaysia for allowing us to perform this study [ID: BP1-01/2019(06)]. This research work of systematic review has been registered on PROSPERO (Registration number: CRD42019135003)

Supplementary material: To access the supplementary material visit the online version of the $J$ Gastrointestin Liver Dis at http://dx.doi. org/10.15403/jgld-818

\section{REFERENCES}

1. Khazaei Z, Sohrabivafa M, Momenabadi V, Moayed L, Goodarzi E. Global cancer statistics 2018: Globocan estimates of incidence and mortality worldwide prostate cancers and their relationship with the human development index. Adv Hum Biol 2019;9:245-250. doi:10.4103/2321-8568.262891

2. Cancer Gernome Atlas Research Network. Comprehensive molecular characterization of gastric adenocarcinoma. Nature 2014;513:202-209. doi:10.1038/nature 13480 
3. Siegel RL, Miller KD, Jemal A. Cancer statistics, 2019. CA Cancer J Clin 2019;69:7-34. doi:10.3322/caac.21551

4. Buckland G, Travier N, Huerta JM, et al. Healthy lifestyle index and risk of gastric adenocarcinoma in the EPIC cohort study. Int J Cancer 2015;137:598-606. doi:10.1002/ijc.29411

5. Lin SH, Li YH, Leung K, Huang CY, Wang XR. Salt processed food and gastric cancer in a Chinese population. Asian Pac J Cancer Prev 2014;15:5293-5298. doi:10.7314/apjcp.2014.15.13.5293

6. Massarrat S, Stolte M. Development of gastric cancer and its prevention. Arch Iran Med. 2014;17:514-520.

7. Coussens LM, Werb Z. Inflammation and cancer. Nature 2002;420:860867. doi:10. 1038/nature01322

8. Cuzick J, Otto F, Baron JA, et al. Aspirin and non-steroidal antiinflammatory drugs for cancer prevention: an international consensus statement. Lancet Oncol 2009;10:501-507. doi: 10.1016/S14702045(09)70035-X

9. Elwood PC, Gallagher AM, Duthie GG, Mur LA, Morgan G. Aspirin, salicylates, and cancer. Lancet 2009;373:1301-1309. doi:10.1016/S01406736(09)60243-9

10. Lim HY, Joo HJ, Choi JH, , et al. Increased expression of cyclooxygenase-2 protein in human gastric carcinoma. Clin Cancer Res 2000; 6:519-525.

11. Wang Z, Chen JQ, Liu JL. COX-2 Inhibitors and Gastric Cancer. Gastroenterol Res Pract. 2014;2014:132320. doi:10.1155/2014/132320

12. Qiao Y, Yang T, Gan Y, et al. Associations between aspirin use and the risk of cancers: a meta-analysis of observational studies. BMC Cancer 2018;18:288. doi:10.1186/s12885-018-4156-5

13. Bosetti C, Rosato V, Gallus S, Cuzick J, La Vecchia C. Aspirin and cancer risk: a quantitative review to 2011. Ann Oncol 2012;23:1403-1415. doi:10.1093/annonc/mds113

14. Moher D, Liberati A, Tetzlaff J, Altman DG, PRISMA Group. Preferred reporting items for systematic reviews and meta-analysis: The PRISMA Statement. PloS Med. 2009;6:e1000097. doi:10.1371/journal. pmed. 1000097

15. Stang A. Critical evaluation of the Newcastle-Ottawa scale for the assessment of the quality of nonrandomized studies in meta-analyses. Eur J Epidemiol 2010;25:603-605. doi:10.1007/s10654-010-9491-Z

16. Review Manager (RevMan) [Computer program]. Version 5.3. Copenhagen: The Nordic Cochrane Centre, The Cochrane Collaboration, 2014.

17. Thun MJ, Namboodiri MM, Calle EE, Flanders WD, Heath CW Jr Aspirin use and risk of fatal cancer. Cancer Res 1993;53:1322-1327.

18. Schreinemachers DM, Everson RB. Aspirin use and lung, colon, and breast cancer incidence in a prospective study. Epidemiology 1994;5:138-146. doi:10.1097/00001648-199403000-00003

19. Wong BC, Zhu GH, Lam SK. Aspirin induced apoptosis in gastric cancer cells. Biomed Pharmacother 1999;53:315-318. doi:10.1016/ S0753-3322(00)88503-0

20. Coogan PF, Rosenberg L, Palmer JR, et al. Nonsteroidal antiinflammatory drugs and risk of digestive cancers at sites other than the large bowel. Cancer Epidemiol Biomarkers Prev 2000;9:119-123.

21. Langman MJ, Cheng KK, Gilman EA, Lancashire RJ. Effect of antiinflammatory drugs on overall risk of common cancer: case-control study in general practice research database. BMJ 2000;320:1642-1646. doi:10.1136/bmj.320.7250.1642

22. Nomura AM, Hankin JH, Kolonel LN, Wilkens LR, Goodman MT, Stemmermann GN. Case-control study of diet and other risk factors for gastric cancer in Hawaii (United States). Cancer Causes Control 2003;14:547-558. doi:10.1023/a:1024887411846
23. Sørensen HT, Friis S, Nørgård B, et al. Risk of cancer in a large cohort of nonaspirin NSAID users: a population-based study. Br J Cancer 2003;88:1687-1692. doi:10.1038/sj.bjc.6600945

24. Gammon MD, Terry MB, Arber N, et al. Nonsteroidal antiinflammatory drug use associated with reduced incidence of adenocarcinomas of the esophagus and gastric cardia that overexpress cyclin D1: a population-based study. Cancer Epidemiol Biomarkers Prev 2004;13:34-39. doi:10.1158/1055-9965.epi-03-0198

25. Trivers KF, De Roos AJ, Gammon MD, Vaughan TL, Risch HA, Olshan AF, et al. Demographic and lifestyle predictors of survival in patients with esophageal or gastric cancers. Clin Gastroenterol Hepatol 2005;3:225-230. doi:10.1016/s1542-3565(04)00613-5

26. Hwang HJ, Youn YH, Kim JH, Chung JB, Lee YC. Low-dose aspirin affects the clinicopathological features of gastric cancer. Digestion 2006;73:54-59. doi:10.1159/000092248

27. Wu CY, Wu MS, Kuo KN, Wang CB, Chen YJ, Lin JT. Effective reduction of gastric cancer risk with regular use of nonsteroidal antiinflammatory drugs in Helicobacter pylori-infected patients. J Clin Oncol 2010;20;28:2952-2957. doi:10.1200/JCO.2009.26.0695

28. Rothwell PM, Fowkes FG, Belch JF, Ogawa H, Warlow CP, Meade TW. Effect of daily aspirin on long-term risk of death due to cancer: analysis of individual patient data from randomised trials. Lancet 2011;377:31-41. doi:10.1016/S0140-6736(10)62110-1

29. Yang L, Zhu H, Liu D, et al. Aspirin suppresses growth of human gastric carcinoma cell by inhibiting survivin expression. J Biomed Res 2011;25,246-253. doi:10.1016/S1674-8301(11)60033-X

30. Jacobs EJ, Newton CC, Gapstur SM, Thun MJ. Daily aspirin use and cancer mortality in a large US cohort. J Natl Cancer Inst 2012;104:12081217. doi:10.1093/jnci/djs318

31. Cook NR, Lee IM, Zhang SM, Moorthy MV, Buring JE. Alternate-day, low-dose aspirin and cancer risk: long-term observational follow-up of a randomized trial. Ann Intern Med 2013;159:77-85. doi:10.7326/00034819-159-2-201307160-00002

32. Shebl FM, Hsing AW, Park Y, et al. Non-steroidal anti-inflammatory drugs use is associated with reduced risk of inflammation-associated cancers: NIH-AARP study. PLoS One 2014;9,e114633. doi:10.1371/ journal.pone.0114633

33. Coyle C, Cafferty FH, Rowley S, et al. ADD-ASPIRIN: A phase III, double-blind, placebo controlled, randomised trial assessing the effects of aspirin on disease recurrence and survival after primary therapy in common non-metastatic solid tumours. Contemp Clin Trials 2016;51:56-64. doi:10.1016/j.cct.2016.10.004

34. Mikami J, Kurokawa Y, Takahashi T, et al. Antitumor effect of antiplatelet agents in gastric cancer cells: an in vivo and in vitro study. Gastric Cancer 2016;19:817-826. doi:10.1007/s10120-015-0556-2

35. Li XF, Xu BZ, Wang SZ. Aspirin inhibits the proliferation and migration of gastric cancer cells in p53-knockout mice. Oncol Lett 2016;12:31833186. doi:10.3892/ol.2016.5067

36. Michigami Y, Watari J, Ito C, et al. Effects of long-term aspirin use on molecular alterations in precancerous gastric mucosa in patients with and without gastric cancer. Sci Rep 2017;7:13384. doi:10.1038/s41598017-13842-x

37. Zhang W, Tan Y, Ma H. Combined aspirin and apatinib treatment suppresses gastric cancer cell proliferation. Oncol Lett 2017;14:54095417. doi:10.3892/ol.2017.6858

38. Spence AD, Busby J, Johnston BT, et al. Low-Dose Aspirin Use Does Not Increase Survival in 2 Independent Population-Based Cohorts of Patients with Esophageal or Gastric Cancer. Gastroenterology 2018;154:849-860.e1. doi:10.1053/j.gastro.2017.10.044 
39. Cheung KS, Leung WK. Long-term use of proton-pump inhibitors and risk of gastric cancer: a review of the current evidence. Therap Adv Gastroenterol 2019;11;12:1756284819834511. doi:10.1177/1756284819834511

40. Watari J, Ito C, Shimoda T, et al. DNA methylation silencing of microRNA gene methylator in the precancerous background mucosa with and without gastric cancer: Analysis of the effects of $\mathrm{H}$ pylori eradication and long-term aspirin use. Sci Rep 2019;9:12559. doi:10.1038/s41598-019-49069-1

41. Watari J, Tomita T, Tozawa K, Oshima T, Fukui H, Miwa H. Preventing Metachronous Gastric Cancer after the Endoscopic Resection of Gastric Epithelial Neoplasia: Roles of Helicobacter pylori Eradication and Aspirin. Gut Liver 2019 Sep 25. doi:10.5009/gn119079

42. Akre K, Ekström A, Signorello L, Hansson L, Nyrén O. Aspirin and risk for gastric cancer: a population-based case-control study in Sweden. Br J Cancer 2001;84:965-968. doi:10.1054/bjoc.2001.1702

43. Bertuccio P, Bravi F, Bosetti C, Negri E, La Vecchia C. Aspirin and gastric cancer risk. Eur J Cancer Prev 2010;19:426-427. doi:10.1097/ CEJ.0b013e32833ecbdc

44. Duan L, Wu AH, Sullivan-Halley J, Bernstein L. Nonsteroidal antiinflammatory drugs and risk of esophageal and gastric adenocarcinomas in Los Angeles County. Cancer Epidemiol Biomarkers Prev 2008;17:126-134. doi:10.1158/1055-9965.EPI-07-0664

45. Farrow DC, Vaughan TL, Hansten PD, et al. Use of aspirin and other nonsteroidal anti-inflammatory drugs and risk of esophageal and gastric cancer. Cancer Epidemiol Biomarkers Prev 1998;7:97-102.

46. Figueroa JD, Terry MB, Gammon MD, et al. Cigarette smoking, body mass index, gastro-esophageal reflux disease, and non-steroidal antiinflammatory drug use and risk of subtypes of esophageal and gastric cancers by P53 overexpression. Cancer Causes Control 2009;20:361368. doi:10.1007/s10552-008-9250-6

47. Fortuny J, Johnson CC, Bohlke K, et al. Use of Anti-Inflammatory Drugs and Lower Esophageal Sphincter-Relaxing Drugs and Risk of Esophageal and Gastric Cancers. Clin Gastroenterol Hepatol 2007;5:1154-1159.e3. doi:10.1016/j.cgh.2007.05.022

48. Gong EJ, Ahn JY, Jung HY, et al. Risk factors and clinical outcomes of gastric cancer identified by screening endoscopy: a case-control study. J Gastroenterol Hepatol 2014;29:301-309. doi:10.1111/jgh.12387

49. Iqbal U, Yang H, Jian W, Yen Y, Li Y. Does aspirin use reduce the risk for cancer? J Investig Med 2016;65:391-392. doi:10.1136/jim-2016-000275

50. Lindblad M, Lagergren J, García Rodríguez LA. Nonsteroidal Antiinflammatory Drugs and Risk of Esophageal and Gastric Cancer. Cancer Epidemiol Biomarkers Prev 2005;14:444-450. doi:10.1158/1055-9965. EPI-04-0467

51. Wang Y, Shen C, Ge J, Duan H. Regular aspirin use and stomach cancer risk in China. Eur J Surg Oncol 2015;41:801-804. doi:10.1016/j. ejso.2015.02.006

52. Zaridze D, Borisova E, Maximovitch D, Chkhikvadze V. Aspirin protects against gastric cancer: Results of a case-control study from Moscow, Russia. Int J Cancer 1999;82:473-476. doi:10.1002/(sici)10970215(19990812)82:4<473::aid-ijc1>3.0.co;2-k

53. Abnet CC, Freedman ND, Kamangar F, Leitzmann MF, Hollenbeck AR, Schatzkin A. Non-steroidal anti-inflammatory drugs and risk of gastric and oesophageal adenocarcinomas: Results from a cohort study and a meta-analysis. Br J Cancer 2009;100:551-557. doi:10.1038/ sj.bjc. 6604880

54. Cheung KS, Chan EW, Wong AYS, et al. Aspirin and Risk of Gastric Cancer After Helicobacter pylori Eradication: A Territory-Wide Study. J Natl Cancer Inst 2018;110:743-749. doi:10.1093/jnci/djx267

55. Epplein M, Nomura AM, Wilkens LR, Henderson BE, Kolonel LN. Nonsteroidal antiinflammatory drugs and risk of gastric adenocarcinoma: the multiethnic cohort study. Am J Epidemiol 2009;170:507-514. doi:10.1093/aje/kwp162

56. Friis S, Sørensen HT, McLaughlin JK, Johnsen SP, Blot WJ, Olsen JH. A population-based cohort study of the risk of colorectal and other cancers among users of low-dose aspirin. Br J Cancer 2003;88:684-688 doi.10.1038/sj.bjc.6600760

57. Kim YI, Kim SY, Kim JH, et al. Long-Term Low-Dose Aspirin Use Reduces Gastric Cancer Incidence: A Nationwide Cohort Study. Cancer Res Treat 2016;48:798-805. doi:10.4143/crt.2015.117

58. Kim MH, Chang J, Kim WJ, Banerjee S, Park SM. Cumulative Dose Threshold for the Chemopreventive Effect of Aspirin Against Gastric Cancer. Am J Gastroenterol 2018;113:845-854.

59. Lee J, Lee SH, Hur KY, Woo SY, Kim SW, Kang WK. Statins and the risk of gastric cancer in diabetes patients. BMC Cancer 2012;12:596. doi:10.1186/1471-2407-12-596

60. Niikura R, Hayakawa Y, Hirata Y, et al. Distinct Chemopreventive Effects of Aspirin in Diffuse and Intestinal-Type Gastric Cancer. Cancer Prev Res 2018;11:279-286. doi:10.1158/1940-6207.CAPR-17-0276

61. Ratnasinghe LD, Abnet C, Qiao YL, et al. Polymorphisms of XRCC1 and risk of esophageal and gastric cardia cancer. Cancer Lett 2004;216:157164. doi:10.1016/j.canlet.2004.03.012

62. Tsoi KKF, Ho JMW, Chan FCH, Sung JJY. Long-term use of low-dose aspirin for cancer prevention: A 10-year population cohort study in Hong Kong. Int J Cancer 2019;145:267-273. doi:10.1002/ijc.32083

63. Kune GA, Kune S, Watson LF. Colorectal cancer risk, chronic illnesses, operations, and medications: case control results from the Melbourne Colorectal Cancer Study. Cancer Res 1988;48:4399-4404.

64. Huang XZ, Chen Y, Wu J, et al. Aspirin and non-steroidal antiinflammatory drugs use reduce gastric cancer risk: A dose-response metaanalysis. Oncotarget 2017;8:4781-4795. doi:10.18632/oncotarget.13591

65. Kong P, Wu R, Liu X, et al. The Effects of Anti-inflammatory Drug Treatment in Gastric Cancer Prevention: An Update of a Metaanalysis. J Cancer 2016;7:2247-2257. doi:10.7150/jca.16524

66. Ye X, Fu J, Yang Y, Gao Y, Liu L, Chen S. Frequency-risk and durationrisk relationships between aspirin use and gastric cancer: a systematic review and meta-analysis. PLoS One 2013;8:e71522. doi:10.1371/ journal.pone.0071522

67. Yang P, Zhou Y, Chen B, et al. Aspirin use and the risk of gastric cancer: a meta-analysis. Dig Dis Sci 2010;55:1533-1539. doi:10.1007/s10620009-0915-0

68. Mueller M, D'Addario M, Egger M, et al. Methods to systematically review and meta-analyse observational studies: a systematic scoping review of recommendations. BMC Med Res Methodol 2018;18:44. doi:10.1186/s12874-018-0495-9

69. Palma S, Delgado-Rodriguez M. Assessment of publication bias in meta-analyses of cardiovascular diseases. J Epidemiol Community Health 2005;59:864-869. doi:10.1136/jech.2005.033027 